\title{
Activities of occupational physicians for occupational health services in small-scale enterprises in Japan and in the Netherlands
}

\author{
Jiro Moriguchi $\cdot$ Masayuki Ikeda $\cdot$ Sonoko Sakuragi $\cdot$ \\ Kazuo Takeda $\cdot$ Takashi Muto $\cdot$ Toshiaki Higashi $\cdot$ \\ André N. H. Weel · Frank J. van Dijk
}

Received: 11 April 2009 / Accepted: 14 January 2010 / Published online: 4 February 2010

(C) The Author(s) 2010. This article is published with open access at Springerlink.com

\begin{abstract}
Objectives Occupational health service (OHS) for smallscale enterprises (SSEs) is still limited in many countries. Both Japan and the Netherlands have universal OHS systems for all employees. The objective of this survey was to examine the activities of occupational physicians (OPs) in the two countries for SSEs and to investigate their proposals for the improvement of service.

Methods Questionnaires on types and sizes of the industries they serve, allocation of service hours (current and desired), sources of information for occupational health activities etc. were mailed in 2006 to 461 and 335 Japanese and Dutch OPs, respectively, who have served in small- and
\end{abstract}

J. Moriguchi $(\varangle) \cdot$ S. Sakuragi

Kyoto Industrial Health Association (Mibu Office),

4-1 Mibu-Sujakucho, Nakagyo-ku, Kyoto 604-8871, Japan

e-mail: moriguchi@kyotokojohokenkai.or.jp

M. Ikeda $\cdot$ K. Takeda

Kyoto Industrial Health Association (Kyoto Office),

Kyoto 604-8472, Japan

T. Muto

Department of Public Health, Dokkyo Medical University,

Tochigi 321-0293, Japan

T. Higashi

Department of Work Systems and Health, Institute of Industrial Ecological Sciences, University of Occupational

and Environmental Health, Japan, Kitakyushu 807-8555, Japan

A. N. H. Weel

Centre of Excellence, Netherlands Society

of Occupational Medicine, 3500 GC Utrecht, the Netherlands

F. J. van Dijk

Coronel Institute of Occupational Health,

Academic Medical Center, University of Amsterdam,

22700 Amsterdam, the Netherlands medium-scale enterprises. In practice, 107 Japanese (23\%) and 106 Dutch physicians (32\%) replied, respectively.

Results and Conclusions Total service time per month was longer for OPs in the Netherlands than OPs in Japan. Japanese OPs spent more hours for health and safety meetings, worksite rounds, and prevention of overwork-induced ill health (14-16\% each). Dutch OPs used much more hours for the guidance of absent workers (48\%). Thus, service conditions were not the same for OPs in the two countries. Nevertheless, both groups of OPs unanimously considered that employers are the key persons for the improvement of OHS especially in SSEs and their education is important for better OHS. The conclusions should be taken as preliminary, however, due to study limitations including low response rates in both groups of physicians.

Keywords Education - Employer - Occupational physician · Occupational health services $\cdot$ Small-scale enterprises

\section{Introduction}

Occupational health service (OHS) activities for small-scale enterprises (SSEs) are often insufficient in many countries (Bradshaw et al. 2001; Park et al. 2002) as they have limited access to human, economic, and technical resources (Champoux and Brun 2003). Thus, workers employed in SSEs are usually provided with lower quality occupational health services (OHS) and sometimes have poorer health conditions when compared with their counterpart workers in large-scale enterprises (Furuki et al. 2006; Kubo et al. 2006). Good OHS require supports of competent $\mathrm{OH}$ professionals (Nicholson 2004), and well-trained occupational physicians (OP) or nurses would be the best experts to provide proper OHS (Bradshaw et al. 2001). 
In Japan, the Industrial Safety and Health (ISH) Law defines that the provision of OHS to protect health of employees is among the duties of employers irrespective of enterprise size and stipulates that companies employing 50 or more workers must establish a health and safety committee and appoint an OP (the number of OPs varies as a function of employee numbers; Ministry of Health, Labour and Welfare, Japan 1972a). The enterprises with less than 50 employees are regarded as SSEs, and Japanese government recently has made several efforts to improve OHS in SSEs. For example, Regional Occupational Health Centers (347 in total) have been established to support OHS.

In the Netherlands, all enterprises have been obliged to have a contract with a certified external OHS after a revision of the Working Conditions Act in 1994 (Weel and Plomp 2007). After further amendment in 2005, employers are no longer obliged to have a full contract with an external OHS provider. Under the condition of an appropriate collective agreement between employers and employees, employers are allowed to arrange legally required $\mathrm{OH}$ activities by themselves. If the results are not satisfactory, however, they should contract with an external OHS provider. A contract with an OP is still compulsory for pre-employment examinations, periodical health examinations, and medical sickness absence guidance activities (Ministry of Social Affairs and Employment, the Netherlands 2006).

Thus, although OHSs for SSEs are not similar, the two countries have established universal OHS for all employees including those in SSEs. The present study was initiated to investigate the activities of OPs in Japan and the Netherlands, with additional foci of collecting suggestions from OPs in the two countries for improvement in OHS in SSEs. It was expected that such study should be valuable for the improvement of the quality of OHS for SSEs not only in the two countries but also in other countries.

\section{Methods}

Study subjects

Participants of the present study in the two counties were OPs who were working in SMEs, and not associated with in-company OHS. A questionnaire survey was conducted in December 2006. Subjects in Japan were OPs who belonged to member external OHS organizations of National Federation of Industrial Health Organizations, Japan (NFIHO). Full-time OPs for large companies and practitioners in clinic/hospital facilities were not affiliated to NFIHO member organizations, and they were automatically excluded from this study. Questionnaires (for details, see below) were mailed to all 461 physicians in NFIHO.
Subjects in the Netherlands were selected from 1,780 physicians who were the members of the Netherlands Society of Occupational Medicine (Nederlandse Vereniging voor Arbeids-en Bedrijfsgeneeskunde, NVAB). Based on the post codes, the country was grouped into 4 regions and $20 \%$ of all OPs from each region were selected. A stratified random sampling strategy by decade of years of age and gender was employed for the selection. After exclusion of apparently non-active physicians (e.g., retired, or exclusively researching or teaching), questionnaires were sent to 335 physicians. Reminder letters were sent only to OPs in the Netherlands and only once.

In practice, 107 Japanese (23\%) and 106 Dutch physicians (32\%) replied, respectively. Of these physicians, 28 Japanese and 17 Dutch physicians were non-active as an OP and they were excluded. In addition, 19 Dutch OPs were full-timers for large companies and were also excluded from the analysis. Thus, effective replies from remaining 79 Japanese $(17 \%)$ and 70 Dutch OP cases (21\%) were employed for analysis.

\section{Questionnaires}

The questionnaires (for details, see the Appendix) included questions on gender, age (by decade of years), working actively as OP or not, working as OP exclusively for one or more large companies or not (only in the Netherlands), experience as an $\mathrm{OP}$ and as a clinician, qualifications for $\mathrm{OP}$, service time (hours per month) as an OP, the number of companies (and the size by employee numbers) serving for, units $(1$ unit $=3 \mathrm{~h})$ spent for each company per month, total number of employees covered, types of industries, estimations of the service hours for different activities and the perceived ideal (desired) service hours for different activities, suggestions on infrastructure to strengthen OHS for SSEs, requests on resources for professional service in $\mathrm{OH}$, and any problems in improving OHS in SSEs as well as possible solutions.

\section{Statistical analysis}

Arithmetic means and modes were taken as representative parameters. When data did not follow normal distribution, Mann-Whitney test and Wilcoxon test were employed as necessary. Chi-squares test was also used. Values of $p<0.05$ were considered statistically significant.

\section{Results}

Basic characteristics

Gender distribution among OPs showed that male dominancy was common in the two countries and it was more so in Japan (men:women $=85 \%: 15 \%)$ than in the Netherlands 
( $68 \%: 32 \% ; p<0.01$ by chi-squares test). Age distributed with a mode of $\geq 60$ years in Japan ( $41 \%$ of all) and 40 59 years in the Netherlands (84\%). Despite the younger age for the Dutch OPs, experience as an OP was significantly longer in the Netherlands [mean (mode) being 10.9 (10) years in Japan versus 16.4 (15) years in the Netherlands; $p<0.01$ by Mann-Whitney test]. Expectedly, Japanese OPs had substantially longer clinical experience than Dutch OPs [mean (mode) being 21.5 (21) years in Japan versus 2.4 (0) years in the Netherlands; $p<0.01$ by Mann-Whitney test].

As to qualifications for OP, $86 \%$ of Japanese OPs had a qualification of the Japan Medical Association (JMA), 10\% had a qualification of the Japan Society for Occupational Health (JSOH), 37\% had a qualification for occupational health consultant of the Japanese Ministry of Health, Labour and Welfare, and 6\% had the Diploma of Occupational Health from the University of Occupational and Environmental Health, Japan. In the Netherlands, $87 \%$ of Dutch OPs had a qualification of registered OP of NVAB, $9 \%$ were still in vocational training for $\mathrm{OP}$, and $3 \%$ had other qualifications (e.g., a registered social insurance physician, medical adviser .).

Comparison of the number of employees covered by one OP showed that Dutch OPs managed a significantly larger number of employees than Japanese OPs; the mean (the mode) of employees covered in Japan was 1,823 employees (1,000 employees) in contrast to 3,227 employees $(2,000$ employees) in the Netherlands $(p<0.01$ by MannWhitney test; the top half in Table 1). It should be noted, however, that one OP serves more than one enterprise. Classification of enterprises covered by OPs showed that Dutch OPs focused more $(85.1 \%)$ in SSEs (with $<50$ employees) than Japanese OPs (11.0\%). Monthly service hours as an OP (the bottom half in Table 1) were longer in the Netherlands [mean (mode) of 24.9 (20) hours) in Japan versus 130.5 (160) hours in the Netherlands; $p<0.01$ by Mann-Whitney test].

Regarding types of industries, manufacturing industries, electricity, gas/water supply companies, and information companies formed a major target of services for OPs in Japan ( 87 out of 232 , or $37.5 \%$ ) than in the Netherlands (46 out of 276 , or $16.6 \% ; p<0.01$ by chi-squares test for the difference). In contrast, education and learning support companies formed a significantly $(p<0.01$ by chi-squares test) larger proportion (23 out of 276 , or $8.3 \%$ ) covered by Dutch OPs than by Japanese OPs (2 out of 232, or $0.9 \%$; Table 2).

\section{Current activities}

Japanese OPs spent a significantly $(p<0.01$ by chi-squares test) larger percentage of hours for attendance at health and safety committee meetings, rounds of the work areas, health and hygiene education, and prevention of health hazards due
Table 1 Distribution of enterprises by employee numbers and distribution of service frequencies

\begin{tabular}{|c|c|c|c|}
\hline Category & $\begin{array}{l}\text { Japanese OPs } \\
\text { No. }(\%)\end{array}$ & $\begin{array}{l}\text { Dutch OPs }{ }^{\mathrm{b}} \\
\text { No. }(\%)\end{array}$ & $P$-value \\
\hline \multicolumn{4}{|c|}{ Enterprise size by number of employees } \\
\hline Mean ${ }^{\mathrm{c}}$ & $1,822.6$ & $3,226.8$ & $<0.01^{\mathrm{d}}$ \\
\hline Mode $^{c}$ & 1,000 & 2,000 & $<0.01^{\mathrm{d}}$ \\
\hline \multicolumn{3}{|c|}{ Classification by category } & $<0.01^{\mathrm{e}}$ \\
\hline Less than 50 & $58(11.0)$ & $4,480(85.1)$ & \\
\hline From 50 to 99 & $183(34.9)$ & $334(6.3)$ & \\
\hline From 100 to 499 & $217(41.4)$ & $355(6.8)$ & \\
\hline From 500 to 999 & $48(9.1)$ & $42(0.8)$ & \\
\hline More than 1,000 & $19(3.6)$ & $54(1.0)$ & \\
\hline Total & $525(100.0)$ & $5,265(100.0)$ & \\
\hline \multicolumn{4}{|c|}{ Frequencies of service by OPs (unit $/$ month) } \\
\hline Mean $^{g}$ & 24.9 & 130.5 & $<0.01^{\mathrm{d}}$ \\
\hline Mode ${ }^{g}$ & 20 & 160 & $<0.01^{\mathrm{d}}$ \\
\hline \multicolumn{3}{|c|}{ Classification by category } & $<0.01^{\mathrm{e}}$ \\
\hline Less than 1 & $294(57.2)$ & $1,443(73.7)$ & \\
\hline From 1 to 4 & $183(35.6)$ & $332(17.0)$ & \\
\hline From 5 to 15 & $34(6.6)$ & $114(5.8)$ & \\
\hline More than 16 & $3(0.6)$ & $69(3.5)$ & \\
\hline Total & $514(100.0)$ & $1,958(100.0)$ & \\
\hline
\end{tabular}

${ }^{\text {a }} n=79$

b $n=70$

c Number of employees

${ }^{d}$ By Mann-Whitney test

e By chi-squares test

${ }^{\mathrm{f}}$ One unit $=3 \mathrm{~h}$

g Monthly service hours as an OP

to overwork (Table 3). The hours spent for general health examinations and mental health care were relatively longer in Japan than in the Netherlands as well, although the differences were statistically insignificant $(p>0.05)$. Dutch OPs used many more hours for guidance of absent workers and spent more hours for the planning and advice on OSH policy than their Japanese counterparts ( $p<0.01$ for both).

Proposed time allocation for $\mathrm{OH}$ activities

From the comparison between current and ideal (desired) working hours of OPs (Table 4), more time for planning and advices on OHS policy, attendance at the health and safety meetings, worksite rounds, activities related to the work environment such as risk assessment and management of work and work environment, health and hygiene education, and health promotion activities were wishes common to both groups. OPs in both countries also wished to preserve more time for general health examination and mental health care. In addition, Japanese OPs wished to 
Table 2 Types of industries for which OPs serve in Japan and in the Netherlands

\begin{tabular}{lrcc}
\hline Type of industries & \multicolumn{2}{c}{ Number of OPs $^{\mathrm{a}}$} & p-value $^{\mathrm{d}}$ \\
\cline { 2 - 3 } & Japanese $^{\mathrm{b}}$ & Dutch $^{\mathrm{c}}$ & \\
\hline Agriculture, forestry, and fishery & 1 & 6 & $<0.10$ \\
Cafe, restaurants, and hotels & 7 & 8 & $>0.10$ \\
Construction & 14 & 24 & $>0.10$ \\
Education and learning support & 2 & 23 & $<0.01$ \\
Electricity, gas and water supply & 11 & 4 & $<0.05$ \\
Finance and insurance & 8 & 9 & $>0.10$ \\
Information and communication & 19 & 11 & $<0.05$ \\
Manufacturing & 57 & 31 & $<0.01$ \\
Medical, health, & 13 & 24 & $>0.10$ \\
$\quad$ and welfare services & & & \\
Mining & 2 & 6 & $>0.10$ \\
Public business & 21 & 29 & $>0.10$ \\
Real estate agent & 2 & 4 & $>0.10$ \\
Services & 21 & 40 & $<0.10$ \\
Transportation & 22 & 27 & $>0.10$ \\
Wholesale or retail trade & 21 & 18 & $>0.10$ \\
Others & 11 & 12 & $>0.10$ \\
\hline
\end{tabular}

${ }^{a}$ Registration by multiple choices

b $n=79$

c $n=70$

${ }^{\mathrm{d}}$ By chi-squares test

increase hours for sick leave guidance and perusal of the answers of 'Other' (responses to an open-end question) showed that they hoped to reduce hours for the after-care of the health examinations (Current: $1.62 \mathrm{~h} \mathrm{month}^{-1}$, Ideal: $0.67 \mathrm{~h} \mathrm{month}^{-1}$ ).

Japanese OPs also wished to increase total working hours as an OP. Dutch OPs wished to decrease the hours spend for sick leave guidance (Table 4) and wanted to increase the hours for specific health examinations, prevention of overwork-induced ill health and health examinations at the initiation of employment compared to current conditions. Similar analyses of 'Other' answers showed that they wished to take more time to improve OPs' quality by attending e.g., quality assurance meetings with colleagues, continuous professional education, and coaching (Current: $1.85 \mathrm{~h}$ month ${ }^{-1}$, Ideal: $1.97 \mathrm{~h} \mathrm{month}^{-1}$ ).

\section{Major information sources}

In Japan, the main resources to support professional work in $\mathrm{OH}$ care were occupational health promotion centers (OHPCs; the major function is to supply information to $\mathrm{OH}$ professionals in the region), the Medical Association, and websites for $\mathrm{OH}$ (Table 5). The main resources in the Netherlands were websites for $\mathrm{OH}$, colleagues in $\mathrm{NVAB}$ and other physicians, and research institutes. Research institutes mentioned were the National Applied Research Organization (TNO) and the Netherlands Centre for Occupational Diseases (NCvB). Educational institutes included the Netherlands School of Public and Occupational Health (NSPOH) and the School for Public and Occupational Health Professionals (SGBO).

Infrastructures to be strengthened

OPs in both countries considered that many aspects of the infrastructure should be strengthened for SSEs. For organizational facilities such as branch-organized (branched by business categories) occupational health centers, demands of both countries were at the same level (answers for "agree strongly" plus "agree": $66 \%$ in Japan, $66 \%$ in the Netherlands, $p>0.10$ by chi-squares test.

The rates of OPs who suggested education and training of employers were very high in both countries (positive answers: $87 \%$ in Japan, $74 \%$ in the Netherlands, $p<0.01)$. The rates were comparable to ( $p>0.10$ in Japan by chi-squares test) or even higher than $(0.10>p>0.05$ in the Netherlands) that for education and training of employees (positive answers: $85 \%$ in Japan, $60 \%$ in the Netherlands, $p<0.01$ ). Demands for the availability of brochures, websites, and other educational materials were also high in both countries (positive answers: $73 \%$ in Japan, $50 \%$ in the Netherlands), being stronger in Japan than in the Netherlands $(p<0.01)$.

\section{Problems and solutions in $\mathrm{OH}$ for SSEs}

OPs in both countries considered that advice by professionals, provision of inexpensive educational courses, and sharing good practices was necessary to improve the insufficient knowledge of employees, health managers, and employers on various $\mathrm{OH}$ matters (results of analyses of other miscellaneous comments in the questionnaires). There were many suggestions for sharing good practices of various $\mathrm{OH}$ activities in both countries. Especially with regard to conditions in workplaces, developments of inexpensive solutions in Japan and more effective solutions based on cost-benefit analysis in the Netherlands were requested.

It was also suggested that opportunities for communication and lectures to deliver $\mathrm{OH}$ information for employers, managers, and employees were insufficient in both countries. Arranging regular opportunities for communication was regarded as important to solve these problems. OPs in the Netherlands considered time and budget for communication as a part of official tasks so that they proposed that a clear statement should be made in the contract with the companies. Necessity of more budgets, by means of e.g., governmental subsidization for $\mathrm{OH}$ activities, was mentioned in both groups of OPs. 
Table 3 Proportion of working hours by types of current activities as an OP in Japan and in the Netherlands

\footnotetext{
a Mean service duration (in hours) was given by each occupational physician, from which the arithmetic means were calculated for Japanese and Dutch physicians

b $n=79$

c $n=70$

${ }^{d}$ By Mann-Whitney test

e (Occupational) health and safety
}

Table 4 Current and ideal working hours per month by the types of activities of OP in Japan and in the Netherlands

${ }^{\text {a }} n=79$

b $n=70$

${ }^{c}$ Mean service duration (in hours) was given by each occupational physician, from which the arithmetic means were calculated for Japanese and Dutch physicians. Unit is in hours/month

${ }^{d}$ By Wilcoxon test

e (Occupational) health and safety

f This question is only to Dutch physicians

\begin{tabular}{|c|c|c|c|}
\hline \multirow[t]{2}{*}{ Types of activities } & \multicolumn{2}{|c|}{ Time allocation by OPs $(\%)^{\mathrm{a}}$} & \multirow[t]{2}{*}{$p$-value ${ }^{\mathrm{d}}$} \\
\hline & Japanese $^{\mathrm{b}}$ & Dutch $^{\mathrm{c}}$ & \\
\hline Attendance at health and safety committee & 13.7 & 1.4 & $<0.01$ \\
\hline Development of comfortable workplaces & 0.8 & 3.8 & $<0.01$ \\
\hline Diagnosis for return to work and follow-up & 7.1 & 3.8 & 0.10 \\
\hline General health examination & 9.5 & 2.9 & 0.22 \\
\hline Guidance of workers on sick leave & 2.5 & 47.8 & $<0.01$ \\
\hline Health and hygiene education & 7.6 & 1.6 & $<0.01$ \\
\hline Health examination at the start of employment & 1.2 & 0.6 & 0.18 \\
\hline Health promotion activity & 4.5 & 1.9 & 0.34 \\
\hline Maintenance and management of work & 1.2 & 2.6 & $<0.01$ \\
\hline Maintenance and management of work environment & 2.1 & 2.3 & $<0.01$ \\
\hline Mental health care & 9.5 & 5.4 & 0.07 \\
\hline Plan and advice for $\mathrm{OHS}^{\mathrm{e}}$ policy & 2.5 & 6.3 & $<0.01$ \\
\hline Pre-employment health examination & 0.5 & 0.8 & $<0.01$ \\
\hline Prevention of health hazards due to overwork & 13.8 & 1.6 & $<0.01$ \\
\hline Risk assessment & 0.3 & 0.8 & $<0.01$ \\
\hline Rounds of the work area & 15.6 & 3.2 & $<0.01$ \\
\hline Specific health examination & 2.5 & 5.1 & $<0.01$ \\
\hline Others & 5.1 & 8.1 & $<0.01$ \\
\hline Total & 100.0 & 100.0 & \\
\hline Total working hours per month & 22.1 & 145.5 & \\
\hline
\end{tabular}

\begin{tabular}{|c|c|c|c|c|c|c|}
\hline \multirow[t]{2}{*}{ Type of activities } & \multicolumn{3}{|c|}{ Japanese OPs ${ }^{\mathrm{a}}$} & \multicolumn{3}{|c|}{ Dutch OPs $^{\text {b }}$} \\
\hline & Current $^{\mathrm{c}}$ & Ideal $^{\mathrm{c}}$ & $P^{\mathrm{d}}$ & Current $^{\mathrm{c}}$ & Ideal $^{\mathrm{c}}$ & $P^{\mathrm{d}}$ \\
\hline Attendance at the meeting of $\mathrm{HS}^{\mathrm{e}}$ committee & 2.3 & 2.8 & $<0.01$ & 2.1 & 5.0 & $<0.01$ \\
\hline Development of comfortable workplaces & 0.3 & 0.8 & $<0.01$ & 4.9 & 5.7 & 0.06 \\
\hline Diagnosis for return to work and follow-up & 2.0 & 2.5 & 0.99 & 6.7 & 8.1 & 0.04 \\
\hline General health examination & 1.8 & 1.5 & 0.37 & 3.8 & 4.1 & 0.35 \\
\hline Guidance of workers on sick leave & 0.8 & 1.9 & $<0.01$ & 64.4 & 39.6 & $<0.01$ \\
\hline Health and hygiene education & 1.1 & 2.0 & $<0.01$ & 2.9 & 6.2 & $<0.01$ \\
\hline Health examination at the start of employment & 0.3 & 0.3 & 0.36 & 0.8 & 2.6 & $<0.01$ \\
\hline Health promotion activity & 0.8 & 1.4 & $<0.05$ & 4.1 & 6.1 & $<0.01$ \\
\hline Maintenance and management of work & 0.3 & 0.8 & $<0.01$ & 5.7 & 6.2 & $<0.01$ \\
\hline $\begin{array}{l}\text { Maintenance and management } \\
\text { of work environment }\end{array}$ & 0.5 & 1.0 & $<0.01$ & 4.3 & 6.4 & $<0.01$ \\
\hline Mental health care & 3.3 & 3.7 & 0.61 & 9.4 & 9.6 & 0.12 \\
\hline Plan and advice for $\mathrm{OSH}^{\mathrm{e}}$ policy & 0.5 & 1.3 & $<0.01$ & 8.1 & 12.3 & $<0.01$ \\
\hline Pre-employment health examination & 0.1 & 0.2 & $<0.01$ & 1.1 & 1.6 & 0.12 \\
\hline Prevention of health hazards due to overwork & 3.1 & 3.9 & 0.24 & 3.2 & 4.8 & 0.04 \\
\hline Rehabilitation during the absent period ${ }^{\mathrm{f}}$ & - & - & - & 21.9 & 20.8 & 0.41 \\
\hline Risk assessment & 0.2 & 0.7 & $<0.01$ & 1.1 & 3.4 & $<0.01$ \\
\hline Rounds of the work area & 2.5 & 3.3 & $<0.01$ & 4.3 & 12.0 & $<0.01$ \\
\hline Specific health examination & 0.7 & 0.7 & $>0.99$ & 7.0 & 11.1 & $<0.01$ \\
\hline Others & 1.7 & 1.7 & 0.72 & 11.8 & 6.2 & $<0.01$ \\
\hline Total & 22.1 & 30.5 & $<0.01$ & 167.4 & 171.5 & $>0.88$ \\
\hline
\end{tabular}


Table 5 Infrastructual facilities to support for the work of OPs in Japan and in the Netherlands

\begin{tabular}{|c|c|c|c|}
\hline \multicolumn{4}{|l|}{ Type of facilities to support for } \\
\hline Japanese OPs ${ }^{\mathrm{a}}$ & $\%$ & Dutch OPs ${ }^{b}$ & $\%$ \\
\hline University of Occupational and Environmental Health & 24.1 & Universities & 28.6 \\
\hline Research institutes including nearby universities & 22.8 & Research institutes & 58.6 \\
\hline Occupational Health Promotion Centers & 54.4 & Educational Institutes & 48.6 \\
\hline \multirow[t]{2}{*}{ Regional Occupational Health Centers } & \multirow[t]{2}{*}{10.1} & Provincial Labour Support & 1.4 \\
\hline & & Municipal Labour Support & 0.0 \\
\hline Medical Association in each prefecture & 40.5 & Colleagues of $\mathrm{NVAB}^{\mathrm{c}}$ and $\mathrm{KNMG}^{\mathrm{c}}$ & 78.6 \\
\hline Labour Inspectorate Bureau in each prefecture & 20.3 & The Regional Labor Inspection Office & 4.3 \\
\hline Ministry of Health, Labour, and Welfare & 17.7 & Ministries $\left(\mathrm{SZW}^{\mathrm{d}}\right.$ and $\left.\mathrm{VWS}^{\mathrm{d}}\right)$ & 27.1 \\
\hline Websites for $\mathrm{OH}$ & 35.4 & Websites for $\mathrm{OH}$ & 80.0 \\
\hline Mailing lists for $\mathrm{OH}^{\mathrm{e}}$ & 13.9 & Mailing lists for $\mathrm{OH}^{\mathrm{e}}$ & 2.9 \\
\hline Others $^{\mathrm{f}}$ & 12.7 & Others $^{\mathrm{g}}$ & 34.3 \\
\hline \multicolumn{4}{|l|}{$n=79$} \\
\hline \multicolumn{4}{|c|}{ b $n=70$} \\
\hline \multicolumn{4}{|c|}{ c NVAB, Netherlands Society of Occupational Medicine; KNMG, The Royal Dutch Medical Association } \\
\hline \multicolumn{4}{|c|}{ d SZW, Ministry of Social Affairs and Employment; VWS, Ministry of Health, Welfare and Sport } \\
\hline \multirow{2}{*}{\multicolumn{4}{|c|}{$\begin{array}{l}\text { e Mailing list is a list of names and e-mail addresses kept on a computer so that members can send a message to a number of people at the same time } \\
\text { f 'Others' in Japan included textbooks, colleagues, instructor physicians, and scientific meetings, etc }\end{array}$}} \\
\hline & & & \\
\hline \multicolumn{4}{|c|}{$\mathrm{g}$ 'Others' in the Netherlands included colleagues, quality assurance by peers, continuous professional education, and OHS organizations, etc } \\
\hline
\end{tabular}

\section{Discussion}

To the knowledge of the authors, this is the first study to analyze and compare the activities of OPs in Japan and the Netherlands, the two countries where all workers are provided $\mathrm{OH}$ care irrespective of enterprise size. The study is also among a few that successfully collect the opinions of active OPs who serve primarily in small- and medium-scale enterprises for the improvements of OHS. As discussed previously, the levels of OHS in SSEs are lower than that in large-scale enterprises (Bradshaw et al. 2001; Park et al. 2002; Furuki et al. 2006; Kubo et al. 2006); it is no need to add that participation of competent OPs and other $\mathrm{OH}$ experts is essential to provide highquality OHS for the development of sound occupational health there (Nicholson 2004).

Probably in reflection of different legal systems in the two countries, OPs in the Netherlands serve longer time ( $146 \mathrm{~h}$ per month) than OPs in Japan (22 h per month; Table 3), and allocation of service time are also different, i.e., OPs in Japan focus their activities on mental health care, attendance at health and safety committees, worksite rounds, and prevention of health hazards due to overwork, where as OPs in the Netherlands gave much more time for guidance of sick leave workers as well as rehabilitation during the absent period (Table 3). Nevertheless, majorities (74-87\%) in both groups of OPs are unanimous in stressing the importance of education and training of employers for good OHS in SSEs. The emphasis was comparable to or even higher than that on edu- cation and training of employees, the traditional target of occupational health education in enterprises.

This suggestion should be quite correct. In a review on preventive occupational health and safety in small enterprises, Hasle and Limborg (2006) summarized that the owner (note that the employer in small business is often the owner-manager) is the dominant actor in relation to any changes made in SSEs and the personal values and priorities of the owner are determinants of the culture, social relations, and the attitude of the enterprises. Thus, the owner is indeed the key person also in occupational health in SSEs. They are also crucial for the development of trust and for the dialog with OPs. Previous reports by Lamm (1997), Nicholson (2004) and Linnan and Birken (2006) are on the same line. In fact, it is an advantage of OPs in SSEs that OPs may have better opportunity to educate the employer not only through the activities of the OHS committee but also by direct conversation with the employer.

In communicating with an employer or an owner-manager, the documents to be submitted to him/her should be short (Brosseau et al. 2007), easy to interpret (Walker and Tait 2004), industry subgroup specific (Mayhew 2000), and carry with practical applications (Mayhew 1997) and good practice examples (Russell et al. 1998). Brosseau and Li (2005) stressed the importance to demonstrate the positive effects of OHS on employee health and to present improved quality outcome. Different time expenditure patterns between Japanese and Dutch OPs may be influenced by legal requirement, at least in part. Dutch OPs devote long hours for sick leave guid- 
ance and rehabilitation (Tables 3, 4) as previously discussed. This may be due to the regulatory requirement that OPs are requested to take care of employees' sickness absence in the Netherlands (Ministry of Social Affairs and Employment, the Netherlands 2006). The fact that Japanese OPs use times for attendance at the safety and health meetings, worksite rounds and prevention of health hazard due to overwork (Tables 3, 4), which are also related to the regulatory stipulation that these are among the duties of OPs in Japan (Ministry of Health, Labour and Welfare 1972a, b, 2005).

Increasing hours for plan and advice for OSH policy and attendance at the meeting of HS committee are common wish in both countries. These might be activities to improve $\mathrm{OH}$ climate in enterprises. Parker et al. (2007) have reported HS committee is the important predictor of workplace safety. Management commitment to safety would result in positive outcome such as job satisfaction and jobrelated performance of employees beyond improved safety performance (Michael et al. 2005).

There are several limitations in this study. Participating OPs in the Netherlands was randomly selected, whereas OPs in Japan were limited to those in member organizations of National Federation of Industrial Health Organizations, Japan, and might not be representative of external OPs in Japan. It is possible that the OPs with a more positive attitude toward $\mathrm{OH}$ activities especially for SSEs were more likely to respond to the questionnaires. Moreover, Japanese OPs in this study are better qualified and presumably more active in $\mathrm{OH}$ than average Japanese external OPs who mostly belong to a clinic or a hospital. There situations might have affected the results of the present study.

Another and possibly more serious problem may be the low response rates, i.e., effective reply rates were $17 \%$ in Japan and $21 \%$ in the Netherlands as previously described in the Methods section. It appears likely that the response rates used to be lower for the medical profession (as in the present study) than for other target populations e.g., patients. Thus, Oudhoff et al. (2007) obtained responses from general practitioners (GPs) and occupational physicians (OPs) at substantially lower rates (32.5 and $46.7 \%$, respectively) than that from patients $(65.6 \%)$ when they sent the same questionnaires on prioritization in surgical waiting lists.

In a questionnaires survey on mutual trust between GPs and OPs in the Netherlands, Nauta and Grumbkow (2001) had an over-all response rate of $23.8 \%$. Further breakdown showed that the rate was $19.6 \%$ for GPs and $36.7 \%$ for OPs. In a survey on required competence of OPs in United Kingdom, Reetoo et al. (2005) intended a questionnaires survey by post but had to switch to telephone interviewing due to a very low response rate.

In Japan, Hirobe et al. (2005) had response from OPs at a rate of $20.4 \%$ when they made a survey on myocardial infarction morbidity of workers. When a questionnaires survey on
OPs' activities in SSEs was conducted, Terada et al. (2005) succeeded to obtain a higher response from OPs at $37.5 \%$ that was achieved when the survey was conducted in cooperation with medical associations in the regions. Muto et al. (1997) reported a similarly high response rate of $37.9 \%$ in a questionnaire survey on the methods to persuade high management to support OHS, but the respondents included non-MDs (such as occupational nurses and safety and health supervisors) and OPs accounted for $37 \%$. Taking these experiences by other study groups into consideration, the response rates in the present study may not be too low.

The structure of the questionnaires used in the present study might have contributed to reduce response rates. The questionnaires set was rather bulky with 20 questions [including some complicated ones (e.g., Q. 11, Q. 12 and Q. 13); see the appendix], and several questions (e.g., Q. 14 and Q. 15) requested answers in free writing. In fact, some OPs in both countries complained in the margin of the questionnaires sheet that "the questionnaire is too complicated and time consuming to complete". The authors could not prepare a reward for the reply as well. These situations might have affected the response rate. There remain several points to be studied. The points include the satisfaction of employers and employees with current OHSs, effectiveness of OHSs to solve or prevent problems, and possible effects of socio-economic factors. They are the subjects of future studies.

In conclusion, the present survey suggests that service patterns are different between OPs in Japan and OPs in the Netherlands, i.e., more time for health and safety committees, worksite rounds, and overwork prevention in cases of Japanese OPs, whereas it is sick leave issues for OPs in the Netherlands. Both groups of OPs consider that the education of employers (possibly owner-managers in cases of SSEa) is important in addition to traditional education of workforces. These conclusions should, however, be taken as preliminary, due to various limitations especially low response rates. Further studies are apparently necessary before reaching solid conclusions.

Acknowledgments We are grateful to the staff in the Coronel Institute of AMC and the Netherlands Society of Occupational Medicine, Mr. Jim de Beer and Miss Fumiko Ohashi who gave invaluable assistance for this study. Thanks are also due to National Federation of Industrial Health Organizations, Japan, Japan Society for Occupational Health, Society for the Study of Occupational Health Promotion, and staff in Kyoto Industrial Health Association, Japan. This work is a part of a scientific study sponsored by the Ministry of Health, Labour and Welfare Japan and is supported by the grant-in-aid from Japan Industrial Safety and Health Association for researchers to study abroad. The survey was conducted during the stay of J. Moriguchi in Coronel Institute of Occupational Health, Amsterdam, the Netherlands in 2006.

\section{Conflict of interest statement None.}

Open Access This article is distributed under the terms of the Creative Commons Attribution Noncommercial License which permits any noncommercial use, distribution, and reproduction in any medium, provided the original author(s) and source are credited. 


\section{Appendix: Sample of the questionnaire for Japanese OPs}

1. Please answer your gender and age.

$\begin{array}{lll}\text { I. Gender } & 1 & \text { Male } \\ \text { II. Age } & 1 & 29 \text { years-old or below } \\ & 2 & 30-39 \text { years-old } \\ & 3 & 40-49 \text { years-old } \\ & 4 & 50-59 \text { years-old } \\ & 5 & 60 \text { years-old or above }\end{array}$

2. Are you active as an occupational physician at this moment?

Yes

*If yes, please answer Q. 4 .

*If no, please kindly answer $\underline{Q .3}$ and send back the questionnaire with the enclosed return envelope. Thank you very much for your co-operation.

3. What is your routine work? It is allowed to indicate more than one box.
(1) General health examination
(2) Specific health examination
(3) Research or teaching
(4) Manager
(5) Retired
(6) Others (please specify)

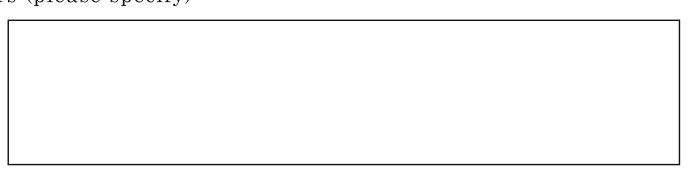

4. Are you only working as an occupational physician in one large company, as an in-company occupational health service?

Yes No

*If yes, it is not necessary to answer the questions below. Please kindly send back the questionnaire with the enclosed return envelope. Thank you very much for your co-operation.

*If no, please answer Q. 5 and below.

5. How long have you worked as an occupational physician?

Years

6. How many hours do you work as an occupational physician a month? Hours/month

7. How many companies do you work for as an occupational physician?

Number of

companies

\begin{tabular}{|l|c|c|}
\hline 1 & Company with less than 50 employees & \\
\hline 2 & Company with from 50 to 99 employees & \\
\hline 3 & Company with from 100 to 299 employees & \\
\hline 4 & Company with from 300 to 499 employees & \\
\hline 5 & Company with from 500 to 999 employees & \\
\hline 6 & Company with more than 1000 employees & \\
\hline
\end{tabular}

8. On the assumption that 1 unit equals 3 hours, how many companies do you work for as an occupational physician in each unit category in a month?

Number of

companies

\begin{tabular}{|l|l|l|}
\hline 1 & Company with less than 1 unit/month & \\
\hline 2 & Company with from 1 to 2 unit/month & \\
\hline 3 & Company with from 3 to 4 unit/month & \\
\hline 4 & Company with from 5 to 8 unit/month & \\
\hline 5 & Company with from 9 to 15 unit/month & \\
\hline 6 & Company with more than 16 unit/month & \\
\hline
\end{tabular}

9. Please answer total number of employees in the companies which you work as occupational physician.
10.Please answer the types of industries for which you work as an occupational physician (please circle all cases).

\begin{tabular}{|c|l|c|l|}
\hline 1 & $\begin{array}{l}\text { Agriculture, forestry and } \\
\text { fishery }\end{array}$ & 10 & Real estate agent \\
\hline 2 & Mining & 11 & $\begin{array}{l}\text { Eating and drinking } \\
\text { facilities, Hotels and } \\
\text { other lodging facilities }\end{array}$ \\
\hline 3 & Construction & 12 & $\begin{array}{l}\text { Medical, health and } \\
\text { wellfare services }\end{array}$ \\
\hline 4 & Manufacturing & 13 & $\begin{array}{l}\text { Education and learning } \\
\text { support }\end{array}$ \\
\hline 5 & $\begin{array}{l}\text { Electricity, gas and } \\
\text { water supply }\end{array}$ & 14 & Services \\
\hline 6 & $\begin{array}{l}\text { Informatnion and } \\
\text { communication }\end{array}$ & 15 & Public business \\
\hline 7 & Transportation & 16 & Others (please specify) \\
\hline 8 & Wholesale or retail trade & 16 & \\
\hline 9 & Finance and insurance & & \\
\hline
\end{tabular}

11. Please answer an estimation of the working hours for different types of activities as an occupational physician at present.

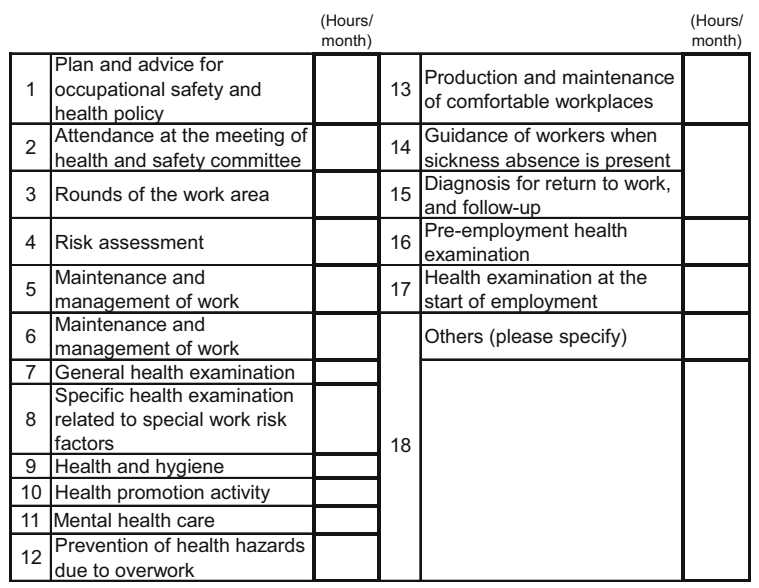

12. Please answer the ideal working hours for different types of activities as an occupational physician.

\begin{tabular}{|c|c|c|c|c|c|}
\hline & & $\begin{array}{l}\text { (Hours/ } \\
\text { month) }\end{array}$ & & & $\begin{array}{l}\text { (Hours/ } \\
\text { month) }\end{array}$ \\
\hline 1 & \begin{tabular}{|l|} 
Plan and advice for \\
occupational safety and \\
health policy
\end{tabular} & & 13 & $\begin{array}{l}\text { Production and maintenance } \\
\text { of comfortable workplaces }\end{array}$ & \\
\hline 2 & $\begin{array}{l}\text { Attendance at the meeting of } \\
\text { health and safety committee }\end{array}$ & & 14 & $\begin{array}{l}\text { Guidance of workers when } \\
\text { sickness absence is present }\end{array}$ & \\
\hline 3 & Rounds of the work area & & 15 & $\begin{array}{l}\text { Diagnosis for return to work, } \\
\text { and follow-up }\end{array}$ & \\
\hline 4 & Risk assessment & & 16 & $\begin{array}{l}\text { Pre-employment health } \\
\text { examination }\end{array}$ & \\
\hline 5 & $\begin{array}{l}\text { Maintenance and } \\
\text { management of work }\end{array}$ & & 17 & $\begin{array}{l}\text { Health examination at the } \\
\text { start of employment }\end{array}$ & \\
\hline 6 & $\begin{array}{l}\text { Maintenance and } \\
\text { management of work }\end{array}$ & & \multirow{7}{*}{18} & Others (please specify) & \\
\hline 7 & General health examination & & & & \\
\hline 8 & $\begin{array}{l}\text { Specific health examination } \\
\text { related to special work risk } \\
\text { factors }\end{array}$ & & & & \\
\hline 9 & Health and hygiene & & & & \\
\hline 10 & Health promotion activity & & & & \\
\hline 11 & Mental health care & & & & \\
\hline 12 & $\begin{array}{l}\text { Prevention of health hazards } \\
\text { due to overwork }\end{array}$ & & & & \\
\hline
\end{tabular}


13. For small-sized companies there might be special problems but also special opportunities and solutions. Can you indicate where you consider special problems and solutions in order to improve occupational health?

We present you some aspects that might be of interest or relevant:

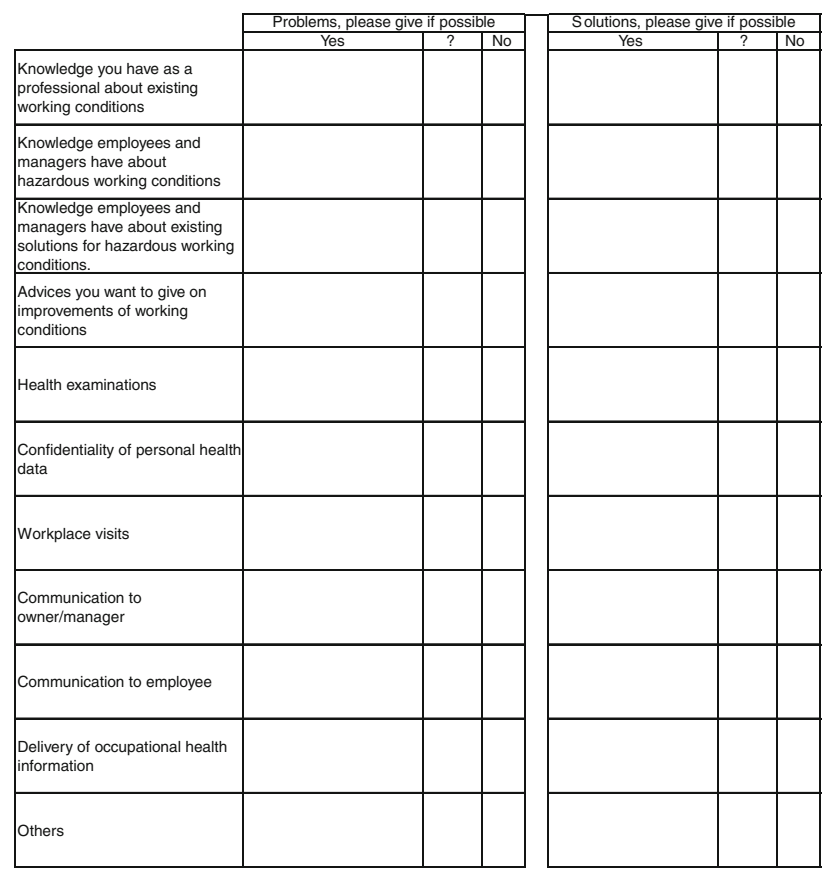

14.Please indicate the activities for which you have problems to carry out as an occupational physician for small-sized companies, if you have problems except for the contents in Q. 13. (please give some

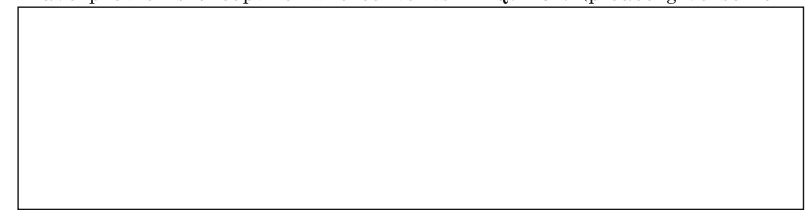

15. Please fill in improvements for occupational health in small-sized companies, if you have suggestions (except for the contents in Q. 12).

16. Please can you indicate which aspects of infrastructure have to be strengthened for small-sized companies?

I. Education and training for employers

Agree strongly Agree Does not matter Disagree Disagree strongly
(1)
(2)
(3)
(4)
(5)

II. Education and training for employees
(1)
(2)
(3)
(4)
(5)

III. Availability of brochures, website, and other educational materials

(2)

(3)

(4)

(5)

IV. Organizational facilities such as branch organized occupational health centers

(1)

(2)

(3)

(4)

(5)
17.Please answer your qualifications for occupational medicine.

1 Certified Occupational Physician of Japan Medical Association

2 Certified Occupational Physician of Japan Society for

Occupational Health

3 Certified Occupational Health Consultant

4 Others

)

18. Where do you get substantial support for your professional work in occupational health? It is allowed to indicate more than one box.

1 University of Occupational and Environmental Health

2 Research organization (e.g. a nearby university)

3 Occupational health promotion center

4 Regional occupational health center

5 Medical association in each prefecture

6 Labour bureau in each prefecture

7 Ministry of Health, Labour, and Welfare

8 Websites for occupational health

9 Mailing lists for occupational health

10 Others ( )

19. How long did you work as a clinician or general practitioner? $\square$ years

20.Please fill in your specialty except for occupational health, if applicable.

\section{References}

Bradshaw LM, Curran AD, Eskin F, Fishwick D (2001) Provision and perception of occupational health in small and medium-sized enterprises in Sheffield, UK. Occup Med (Lond) 51:39-44

Brosseau LM, Li SY (2005) Small business owners' health and safety intensions: a cross-sectional survey. Environ Health A Glob Access Sci 4:23

Brosseau LM, Fredrickson AL, Casey MA (2007) Small business owners' opinions about written health and safety information. Ind Health 45:209-216

Champoux D, Brun J-P (2003) Occupational health and safety management in small size enterpriseees; an overview of the situation and avenues for intervention and research. Safety Sci 41:301-318

Furuki K, Hirata M, Kage A (2006) Nationwide survey of occupational health activities in small-scale enterprises in Japan. Ind Health 44:150-154

Hasle P, Limborg HJ (2006) A review of the literature on preventive occupational health and safety activities in small enterprises. Ind Health 44:6-12

Hirobe K, Terai T, Fujioka S, Goto K, Dohi S (2005) Morbidity of myocardial infarction multicenter study in Japan (3 M study). Circulation J 69:767-773

Kubo N, Usami T, Haruyama Y, Muto T, Kimura K, Yukawa S, Kimura T, Yamane N (2006) Characteristics of lifestyle and health status of workers in small-scale enterprises in Japan. Ind Health 44:161-165

Lamm F (1997) Small businesses and OH\&S advisors. Safety Sci 25:153-161

Linnan LA, Birken BE (2006) Small businesses, worksite wellness, and public health: a time for action. NC Med J 67:433-437

Mayhew C (1997) Small business occupational health and safety information provision. J Occup Health Safety Aust-NZ 13:361-373 J Occup Health Safety Aust-NZ 16:297-305 
Mayhew C (2000) OHS in Australian "micro" small business: evidence from nine research studies. J Occup Health Safety Aust-NZ 16:297-305

Michael JH, Evans DD, Jansen KJ, Haight JM (2005) Management commitment to safety as organizational support: relationships with non-safety outcomes in wood manufacturing employees. J Safety Res 36:171-179

Ministry of Health, Labour and Welfare, Japan (1972a) Industrial Safety and Health Law (Law No. 13, 18). Ministry of Health, Labour and Welfare, Tokyo (in Japanese)

Ministry of Health, Labour and Welfare, Japan (1972b) Industrial Safety and Health Regulation (Regulation No. 15). Ministry of Health, Labour and Welfare, Tokyo (in Japanese)

Ministry of Health, Labour and Welfare, Japan (2005) Industrial Safety and Health Regulation (Regulation No. 52 Paragraph 2). Ministry of Health, Labour and Welfare, Tokyo (in Japanese)

Ministry of Social Affairs, Employment (Ministerie van Sociale Zaken en Werkgelegenheid), the Netherlands (2006) Working conditions act (Act No. 673). Ministry of Social Affairs and Employment, the Netherlands (in Dutch)

Muto T, Tomita M, Kikuchi S, Watanabe T (1997) Methods to persuade higher management to invest health promotion programmes in the workplace. Occup Med 47:210-216

Nauta AP, von Grumbkow J (2001) Factors predicting trust between GPs and Ops. Int J Integr Care 1:e31

Nicholson PJ (2004) Occupational health services in the UK-challenges and opportunities. Occup Med (Lond) 54:147-152

Oudhoff JP, Timmermans DRM, Knol DL, Bijnen AB, Van der Wal G (2007) Prioritising patients on surgical waiting lists: a conjoint analysis study on the priority judgements of patients, surgeons, occupational physicians, and general pracitioners. Soc Sci Med 64:1863-1875

Park H, Ha E, Kim J, Jung H, Paek D (2002) Occupational health services for small-scale enterprises in Korea. Ind Health 40:1-6

Parker D, Brosseau L, Samant Y, Pan W, Xi M, Haugan D, Study Advisory Board (2007) A comparison of the perceptions and beliefs of workers and owners with regard to workplace safety in small metal fabrication businesses. Am J Ind Med 50:999-1009

Reetoo KN, Harrington JM, Macdonald EB (2005) Required competencies of occupational physicians: a Delphi survey of UK customers. Occup Environ Med 62:406-413

Russell RM, Maidment SC, Brooke I, Topping MD (1998) An introduction to UK schemes to help small firms control health risks from chemicals. Ann Occup Hyg 68:699-704

Terada H, Sone T, Takemura S (2005) A study on actual situation of community industrial physicians for small and medium-sized enterprises and their involvement in community occupational health services. Sangyo Eiseigaku Zasshi 47:259-268 (in Japanese with English abstract)

Walker D, Tait R (2004) Health and safety management in small enterprises; an effective low cost approach. Safety Sci 42:69-83

Weel AN, Plomp HN (2007) Developments in occupational health services in the Netherlands: from a professional to a market regime. Supporting health at work: international perspectives on occupational health services, policy and practice in health and safety, institution of occupational safety and health issue 1 Suppl:87-101 